Comparison of Injury Severity Between Moped and Motorcycle Crashes: A Finnish Two-Year Prospective Hospital-Based Study

\title{
Airaksinen, N.
}

2016-03

Airaksinen , N , Nurmi-Luthje , I \& Luthje , P 2016, ' Comparison of Injury Severity Between Moped and Motorcycle Crashes : A Finnish Two-Year Prospective Hospital-Based Study ' , Scandinavian Journal of Surgery, vol. 105 , no. 1 , pp. 49-55 . https://doi.org/10.1177/1457496915571401

http://hdl.handle.net/10138/161322

https://doi.org/10.1177/1457496915571401

publishedVersion

Downloaded from Helda, University of Helsinki institutional repository.

This is an electronic reprint of the original article.

This reprint may differ from the original in pagination and typographic detail.

Please cite the original version. 


\title{
COMPARISON OF INJURY SEVERITY BETWEEN MOPED AND MOTORCYCLE CRASHES: A FINNISH TWO-YEAR PROSPECTIVE HOSPITAL-BASED STUDY
}

\author{
N. Airaksinen ${ }^{1}$, I. Nurmi-Lüthje ${ }^{2}$, P. Lüthje ${ }^{3}$ \\ ${ }^{1}$ Department of Business Information Management and Logistics, Tampere University of Technology, \\ Tampere, Finland \\ ${ }^{2}$ Department of Public Health, Hjelt Institute, University of Helsinki, Helsinki, Finland \\ ${ }^{3}$ Department of Orthopaedics and Traumatology, North Kymi Hospital, Kuusankoski, Finland
}

\section{ABSTRACT}

Background and Aims: The coverage of the official statistics is poor in motorcycle and moped accidents. The aim of this study was to analyze the severity of motorcycle and moped crashes, and to define the degree of under-reporting in official statistics.

Material and Methods: All first attendances due to an acute motorcyclist or moped driver injury registered in the emergency department between June 2004 and May 2006 were analyzed. The severity of the injuries was classified using the Abbreviated Injury Scale score and the New Injury Severity Score. The hospital injury data were compared to the traffic accident statistics reported by the police and compiled and maintained by Statistics Finland.

Results: A total of 49 motorcyclists and 61 moped drivers were involved in crashes, leading to a total of 94 and 109 injuries, respectively. There were slightly more vertebral and midfoot fractures among motorcyclists than among moped drivers $(p=0.038$ and 0.016 , respectively). No significant differences were found between the severity (maximum Abbreviated Injury Scale and median New Injury Severity Scores) of the motorcycle and moped crashes. There was no in-hospital mortality. The degree of agreement (overlap) between the hospital dataset and the official statistics was $32 \%$. The rate of under-reporting was $68 \%$.

Conclusions: According to the maximum Abbreviated Injury Scale and New Injury Severity Scores, the injury severity was equal for motorcycle and moped crashes. The degree of agreement between the hospital dataset and the official statistics was $32 \%$.

Key words: Motorcycle; moped; injury; injury severity; under-reporting; mortality

Correspondence:

Peter Lüthje

Department of Orthopaedics and Traumatology

North Kymi Hospital

FI-45750 Kuusankoski

Finland

Email: peter.luthje@pp.inet.fi
Scandinavian Journal of Surgery

2016, Vol. 105(1) 49-55

(c) The Finnish Surgical Society 2015

Reprints and permissions:

sagepub.co.uk/journalsPermissions.nav

DOI: $10.1177 / 1457496915571401$

sjs.sagepub.com

(S)SAGE 


\section{INTRODUCTION}

Riding motorcycles and mopeds is increasing in Finland. Between 2000 and 2012, the number of motorcycles and mopeds increased by $170 \%$ and $186 \%$, respectively (1). Both activities are risky. According to one US investigation, motorcyclists are 35 times more likely than passenger-car occupants to die in a motor vehicle traffic accident, and eight times more likely to be injured per vehicle mile (2). A Canadian study showed that motorcyclists are more than 3.5 times more likely to be injured or die than other motor vehicle drivers (3). Research from Sweden reports a 20 times higher risk of injury associated with traveling by moped than by car (4). A German study showed that adolescents driving mopeds had a 24-fold risk of injury compared to bicyclists (5).

In Finland, a moped or scooter is a vehicle with an engine displacement of at most $50 \mathrm{cc}$, and the top speed limit is $45 \mathrm{~km} / \mathrm{h}$. Since October 2005 , it has been legal to have a passenger on a moped or scooter. Two-wheeled vehicles with higher engine displacements and speeds above $45 \mathrm{~km} / \mathrm{h}$ are classified as motorcycles.

Traffic safety assessments in Finland are based on the official traffic accident statistics reported by the police and maintained by Statistics Finland. The statistics on fatal traffic accidents are correct, but those on injured subjects are insufficient (6). The Finnish authorities define a fatal vehicle accident as a roadtraffic accident causing the death of any person at the scene, on arrival at hospital, or within 30 days of the event (7). The development of the national injury statistics indicates that the coverage of the official statistics is poorest in bicycle accidents and second poorest in motorcycle and moped accidents (8).

In Finland, little is known about the severity of injuries caused by motorcycle and moped crashes. The classification of injury severity is neither used in clinical work nor recorded in national injury statistics in Finland. In 2013, the European Union (EU) issued a recommendation to all member states on the definition of serious injury and the compilation of statistics on serious injuries in traffic accidents (9).

The aim of this study was, using hospital injury data, to analyze the injury patterns and injury severity of motorcycle and moped (including scooter) crashes, and to define the level of under-reporting of these crashes in official statistics. Since these two-wheeled motor vehicles differ from each other in power and speed, our hypothesis is that the injuries of motorcyclists are more severe than those of moped drivers.

The present case is a first study in Finland with regard to the definition of serious injuries in motorcycle and moped accidents.

\section{MATERIALS AND METHODS}

\section{STUDY DESIGN}

We registered prospectively consecutive motorcycle and moped accident victims who attended the Emergency Department at the North Kymi Hospital, Kouvola, Finland, during 2 years from June 1, 2004 to May 31, 2006. During that time period, we could collect the injury data directly in the electronic patient record system, via the injury database created for this purpose. According to population statistics in study years, the North Kymi Hospital (level II trauma center) was responsible for an area with nearly 100,000 inhabitants. The catchment area is a typical area in Finland, with urban and rural municipalities.

\section{DATA}

The International Classification for Diseases (ICD-10Finnish Modification) (10), for public hospital use in Finland was used. Motorcycle and moped crashes were identified according to the external cause of injury (codes V28-V29 in ICD-10, FM). These codes are equivalent to the ICD-10 codes V20-V29 (http:/ / www.who.int/classifications). In addition, the following data were gathered: age, sex, date and time of accident, type of accident (ICD-10), and trauma diagnoses (ICD-10). Breath alcohol concentration (BAC) on attendance was routinely tested with a breathalyzer by staff in the emergency department, and was expressed as $\mathrm{g} / \mathrm{L}$. In addition, treatment of injury, admittance to the hospital, referral to the central hospital or university hospital, use of a helmet, and number of operations were checked retrospectively in the patients' hospital records. Corresponding medical data on patients who were referred to the Kymenlaakso Central hospital in Kotka or to the Central University Hospital in Helsinki (level I trauma center) were checked and gathered by one of the present authors (P.L.), an orthopedist and trauma surgeon. These patients were included in our data.

Whether the vehicle in question was a motorcycle or a moped was identified from the patient's hospital records. The external cause of injury classification (ICD-10) does not include separate codes for a motorcycle crash or a moped crash.

The severity of the injuries was classified retrospectively according to the Abbreviated Injury Scale (AIS) (11) by P.L. Maximum Abbreviated Injury Scale (MAIS) denotes maximum AIS. Furthermore, as a complementary classification to MAIS, the New Injury Severity Score (NISS) was calculated. The NISS (12) is a simple modification to the Injury Severity Score ISS (13). ISS does not take into account multiple injuries in the same body region. NISS sums squares of the three most severe injuries, regardless of body region injured.

The hospital injury data were compared to the official traffic accident statistics reported by the police and compiled by Statistics Finland. The comparison was made on the basis of the date, time, location, and type of the cases. In addition, the number of prehospital fatal cases in the study area during the study period was checked from Statistics Finland.

\section{STATISTICAL ANALYSIS}

Analyses were performed using SPSS Statistics 22. Fisher's exact test, the Pearson chi-square test, the Wilcoxon rank test, and the Independent Samples t-test were used. The values are expressed as mean \pm standard deviation $(S D)$ or median with $25 \%$ and $75 \%$ interquartiles unless otherwise mentioned. 


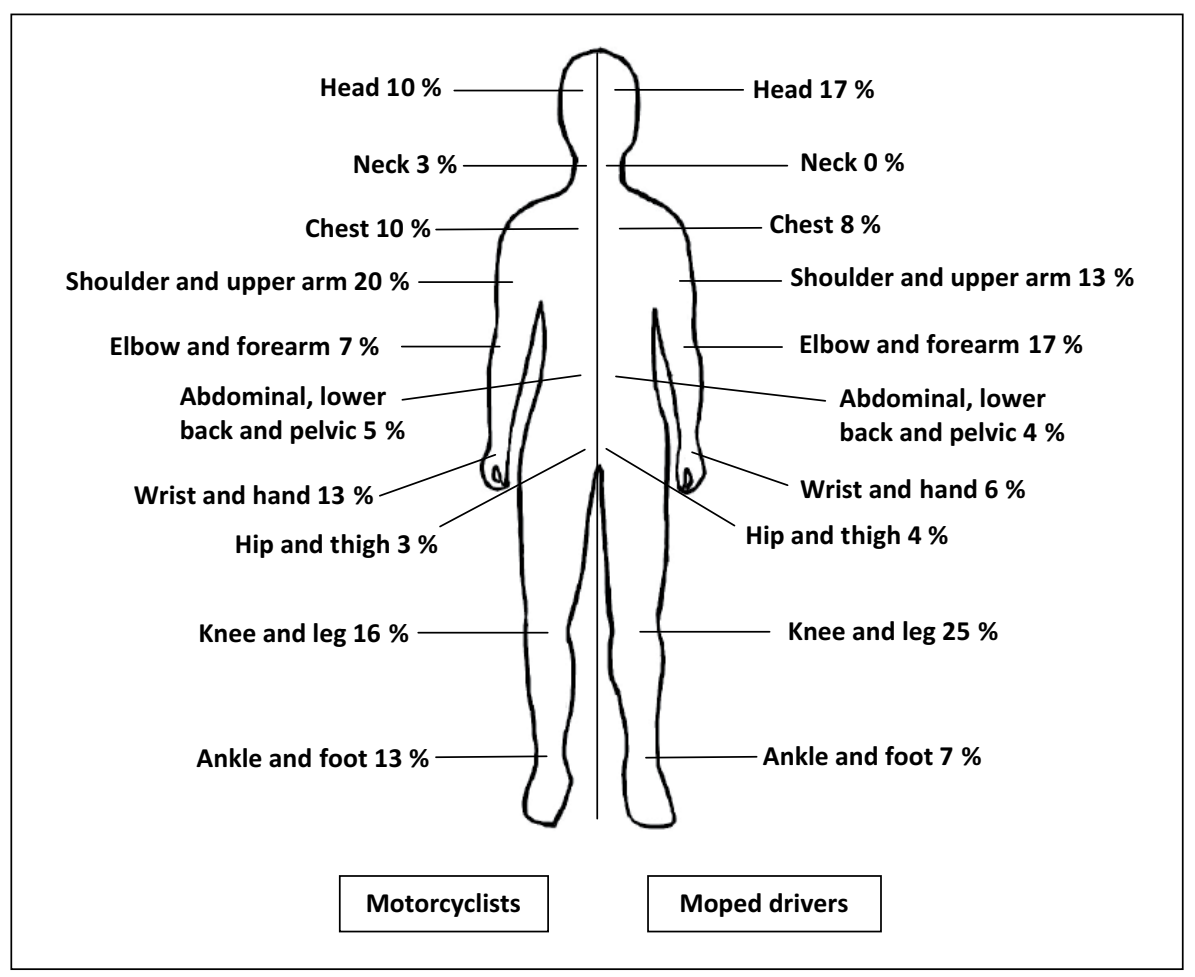

Fig. 1. Body region of injury for motorcyclists and moped drivers.

A p-value of $<0.05$ was considered statistically significant.

\section{RESULTS}

Over 2 years, a total of 49 motorcyclists and 61 moped drivers were involved in crashes, leading to a total of 94 and 109 injuries, respectively. Two injured motorcyclists and one injured moped driver were pillion passengers. The figures for male motorcyclists and moped drivers were $88 \%(n=43)$ and $70 \%(n=43)$, respectively $(p=0.029)$. The motorcyclists were quite evenly distributed by age, whereas moped drivers were most often $(70 \%)$ in the age group $15-17$ years. The mean age of motorcyclists was 32.4 years \pm 13.3 years and that of moped drivers $21.4 \pm 14.5$ years $(p=0.000)$. Male motorcyclists were $32.8 \pm 13.7$ years and females $29.1 \pm 11.0$ years $(p=0.458)$, whereas the male moped drivers were $21.6 \pm 15.2$ years and females $21.1 \pm 12.8$ years $(p=0.780)$.

\section{INJURIES}

The anatomical locations of all injuries among motorcyclists and moped drivers are shown in Fig. 1. The most common injuries among motorcyclists and moped drivers were shoulder and upper extremity injuries (38/94, 40\% and 39/109, 36\%, respectively) $(\mathrm{p}=0.296)$ and lower extremity injuries $(30 / 94,32 \%$ and $39 / 109,36 \%$, respectively $(\mathrm{p}=0.334))$. There were slightly more neck injuries among motorcyclists $(\mathrm{p}=0.038)$, and, correspondingly, slightly more elbow and forearm injuries among moped drivers $(p=0.039)$. The figures of head injuries were $9.6 \%(9 / 94)$ and
$16.5 \%(18 / 109)$ in motorcyclists and moped drivers, respectively $(p=0.106)$. Severe head injuries (MAIS $\geqslant 3$ ) were 33\% (3/9) among motorcyclists and 11\% (2/18) among moped drivers $(\mathrm{p}=0.189)$.

A total of 34 motorcyclists and 41 moped drivers sustained fractures. More vertebral and midfoot fractures appeared among motorcyclists than among moped drivers $(\mathrm{p}=0.038$ and $\mathrm{p}=0.016$, respectively) (Table 1). Motorcyclists sustained $13(38 \%, 13 / 34)$ and moped drivers 15 fractures $(37 \%, 15 / 41)$ of the upper extremity ( $\mathrm{p}=0.464)$, and, respectively, $17(50 \%, 17 / 34)$ and 12 fractures $(29 \%, 12 / 41)$ of the lower extremity $(p=0.055)$. Furthermore, motorcyclists sustained 21 and moped drivers 18 other unspecified fractures $(p=0.095)$. Each moped driver sustained, on average, 1.1 fractures, and each motorcyclist, correspondingly, 1.5 fractures. In all, $32.4 \%(11 / 34)$ of the moped drivers and $36.6 \%(15 / 41)$ of the motorcyclists who sustained fractures were operated on for a fracture $(p=0.446)$. In total, there were 20 operations on moped drivers and 26 operations on motorcyclists $(p=0.498)$.

\section{INJURY SEVERITY}

No differences were found between the two groups, according to AIS and MAIS scores (Tables 2 and 3). No differences were found in the median NISSs, either, with the median NISSs being 4.0 in both groups.

The distribution of serious injuries (MAIS $\geqslant 3$ ) in motorcycle crashes was similar regardless of the gender of the patient, with males $7 / 43(16 \%)$ and females $1 / 6(17 \%)(p=0.322)$. In moped crashes, the corresponding figures were $10 / 43(23 \%)$ and $2 / 18$ $(11 \%)(p=0.237)$. 
TABLE 1

Distribution of fractures among 34 motorcyclists $(n=51)$ and 41 moped drives $(n=45)$ according to body region.

\begin{tabular}{|c|c|c|c|c|}
\hline & $\begin{array}{l}\text { Factures due to } \\
\text { motorcycle crashes }\end{array}$ & $\begin{array}{l}\text { Fractures due to } \\
\text { moped crashes }\end{array}$ & Total & $\mathrm{p}^{*}$ \\
\hline Fracture & n (\%) & n (\%) & n $(\%)$ & \\
\hline Skull/face & $2(4)$ & $4(9)$ & $6(6)$ & NS \\
\hline Clavicle & $6(12)$ & $7(16)$ & $13(14)$ & NS \\
\hline Scapula & $3(6)$ & $2(4)$ & $5(5)$ & NS \\
\hline Humerus & $1(2)$ & $1(2)$ & $2(2)$ & NS \\
\hline Forearm & $10(20)$ & $12(27)$ & $22(23)$ & NS \\
\hline Hand & $2(4)$ & $2(4)$ & $4(4)$ & NS \\
\hline Vertebral & $4(8)$ & - & $4(4)$ & $\mathrm{p}=0.038$ \\
\hline $\mathrm{Rib}$ & $4(8)$ & $5(11)$ & $9(10)$ & NS \\
\hline Pelvis & $2(4)$ & - & $2(2)$ & NS \\
\hline Femur & $1(2)$ & $1(2)$ & $1(1)$ & NS \\
\hline Patella & $1(2)$ & - & $1(1)$ & NS \\
\hline Tibia/fibula & $3(6)$ & $9(20)$ & $12(13)$ & NS \\
\hline Ankle & $5(10)$ & $1(2)$ & $6(6)$ & NS \\
\hline Midfoot & $5(10)$ & - & $5(5)$ & $p=0.016$ \\
\hline Forefoot & $2(4)$ & $1(2)$ & $3(3)$ & NS \\
\hline Total & 51(100) & $45(100)$ & $96(100)$ & NS \\
\hline
\end{tabular}

NS: not significant.

*Fisher's exact test.

TABLE 2

Severity (AIS) of injuries among 49 motorcyclists $(n=94)$ and 61 moped drivers $(n=109)$

\begin{tabular}{llc}
\hline AIS scores & $\begin{array}{l}\text { Injuries of } \\
\text { motorcyclists, } \mathrm{n}(\%)\end{array}$ & $\begin{array}{l}\text { Injuries of moped } \\
\text { drivers, } \mathrm{n}(\%)\end{array}$ \\
\hline AIS 1 = minor & $46(49)$ & $63(58)$ \\
AIS 2 = moderate & $39(41)$ & $33(30)$ \\
AIS 3 = serious & $7(7)$ & $12(11)$ \\
AIS 4 = severe & $2(2)$ & $1(1)$ \\
Total & $94(100)$ & $109(100)$ \\
\hline
\end{tabular}

AIS: Abbreviated Injury Scale; NS: not significant.

Wilcoxon rank test $=0.867$, NS.

TABLE 3

Severity of the most serious injury (MAIS) of motorcycle crashes $(n=49)$ and moped crashes $(n=61)$.

\begin{tabular}{lll}
\hline MAIS scores & $\begin{array}{l}\text { Motorcycle } \\
\text { crashes, } \mathrm{n}(\%)\end{array}$ & $\begin{array}{l}\text { Moped } \\
\text { crashes, } \mathrm{n}(\%)\end{array}$ \\
\hline MAIS 1 = minor & $15(31)$ & $22(36)$ \\
MAIS 2 = moderate & $26(53)$ & $27(44)$ \\
MAIS 3 = serious & $6(12)$ & $11(18)$ \\
MAIS 4 = severe & $2(4)$ & $1(2)$ \\
Total & $49(100)$ & $61(100)$ \\
\hline
\end{tabular}

MAIS: maximum Abbreviated Injury Scale; NS: not significant. Wilcoxon rank test $=-0.347$, NS.

\section{USE OF HELMETS AND DRIVING UNDER THE INFLUENCE OF ALCOHOL}

Two motorcyclists $(4 \%)$ and three moped drivers (5\%) were not wearing a helmet. In four moped crashes, the helmet fell off during the crash. All the injured motorcyclists were sober. In six moped crashes $(10 \%)$, five drivers, most often (4/5) a male driver, and one pillion moped driver were under the influence of alcohol.

\section{MORTALITY}

There was no in-hospital or 1-year mortality. However, official statistics showed that during the study period in the study area, four motorcyclists $(7.6 \%, 4 / 53)$ and one moped driver $(1.6 \%, 1 / 62)$ died at the scene of the accident $(p=0.137)$. Thus, the 30 -day mortality rates for motorcyclists and moped drivers were 2.2 and 0.62 per 100,000 persons, respectively.

\section{COMPARISON BETWEEN HOSPITAL DATA AND OFFICIAL STATISTICS}

Only 35 patients from those in the hospital data were identified in the official statistics, the degree of agreement being 32\% (35/110). Thus, the rate of underreporting was $68 \%$. The extent to which the serious injuries (MAIS $\geqslant 3$ ) were found in the official statistics was $55 \%(11 / 20)$.

The majority of crashes $(69 \%, 76 / 110)$ were singleparty accidents, that is, without another party, for example, another vehicle or a pedestrian. If there was another party involved, it was most commonly a car. Most of the collisions $(68 \%, 23 / 34)$ between a motorcyclist or moped driver and a car were recorded in the official statistics. Only $16 \%$ of the single-party crashes appeared in the official statistics.

\section{DISCUSSION}

Our results indicate that there are no significant differences in the injury severity between motorcycle and 
moped crashes. Both AIS scores (11) and NISSs (12) were used in this study. Similar results were reported in a Danish study of non-fatal accidents among motorcyclists and moped and scooter drivers (14), in an Australian study (15) and in a recent Dutch study (16). However, light-moped drivers (permitted maximum speed of $25 \mathrm{~km} / \mathrm{h}$ ) showed more severe injuries than moped riders and motorcyclists (16). The Danish study (14) used the AIS classification, the Australian study (15) the ISS classification (13), and the Dutch study (16) both the AIS and ISS classifications. In 2013, the use of AIS scores (MAIS $\geqslant 3$ ) was recommended by the EU to all member states concerning the definition of serious injury in traffic accidents (9).

Our results indicate that traffic injuries with twowheeled motor vehicles are much more common among males than females. Other studies have shown similar results (14-16).

As reported elsewhere (14-18), upper and lower extremities were most commonly injured. In a Dutch study, similar to our results, the most common injuries among motorcyclists were those of the upper extremities, and among moped riders, correspondingly, the lower extremities (16). But then again, in Australia, the lower extremities were the most common region among both moped/scooter riders (42\%) and motorcycle riders $(44 \%)(15)$.

In the Swedish studies, the motorcyclists had five times more vertebral fractures $(17,18)$ and 2.5 times more upper extremity fractures than the moped drivers (19). In the present study, there were more vertebral fractures among motorcycle drives, but the figures for upper extremity fractures among motorcyclists and among moped drivers sustaining fractures were equal (37\%) to those in the Danish study (14).

The corresponding figures for the lower extremities were different: $50 \%$ versus $29 \%$. The results of the present study differ from other studies, in which the most common site for fractures in moped drivers (20) and in motorcyclists $(21,22)$ was the lower extremities.

Our study showed no differences in mortality between motorcyclists and moped drivers. All deaths occurred at the scene of the accident, and none during the in-hospital stay or during the first year. Our total rate of deaths of motorcyclists was $7.6 \%$ and of moped drivers $1.6 \%$, and the mortality rates were 2.2 and 0.62 per 100,000 persons, respectively.

In the Swedish 8-year study (1987-1994), the inhospital mortality rate was $1 \%$ among moped riders (17), and within 30 days of admission, the mortality rate was $0.9 \%$ among motorcyclists and $1.6 \%$ among passengers (18). If deaths after 30 days were included, the total rate of deaths of motorcyclists was $2.2 \%$ and of passengers 3.3\% (driver plus passenger: 2.3\%) (18). In a Dutch study (1993-2008), the mortality after admission to hospital was $2.5 \%$ among motorcyclists and $2.1 \%$ among moped riders (16). In Australia, the mortality rate (July 2002-June 2008) among motorcyclists was 4.2 per 10,000 registration years, compared with 1.2 fatalities for moped riders (23). In neither study was information on the follow-up time of mortality reported $(16,23)$.

Weiss et al. (24) reported the influence of the three major and different types of helmet laws in the United
States: (1) for all ages (universal), (2) for people younger than 21 years ( $<21$ law), and (3) for children younger than 18 years $(<18$ law). In states with the $<21$ law, serious traumatic brain injuries among youths were $38 \%$ higher than in states with the universal law. Motorcyclists aged 12-17years in $<18$ helmet law states had a higher proportion of serious-severe traumatic brain injuries than motorcyclists in universallaw states (24). A number of authors have suggested that the major cause of death following two-wheeled motor accidents is head injury (25-27). In Finland, the use of helmets among motorcyclists and moped drivers is mandatory, but $5 \%$ of the present study population was not wearing a helmet. In our study, the rates in head injuries were equal among motorcyclists and moped drivers, and similar result was found in the severe head injuries. In Denmark (14), no differences in severe head injuries were found between motorcyclists and moped drivers, either.

The recent Dutch study reported slightly more severe injuries and mortality among motorcyclists than among moped riders $(\mathrm{p}<0.05)(16)$. In the lightmoped group (helmet not obligatory), half of all severe injuries concerned head injuries (49.3\%) (16).

\section{THE DEGREE OF AGREEMENT (OVERLAP) OF THE DIFFERENT DATA SOURCES}

In most countries, data on road-traffic injuries are provided by the police, and road safety policies are based on that data. Under-reporting is common in studies of bicycle injuries, two-wheeled motor vehicle injuries, and car accidents $(6,28,29)$. In the present study, the degree of agreement of hospital data and official statistics in non-fatal motorcycle and moped accidents was $32 \%$, and half of the severe injuries occurring in hospital data were found in official statistics. A study from the United Kingdom reported that only $50 \%$ of the police road-traffic accident injury admissions were included in the linked database of hospital admissions (28). The linkage rate was $31 \%$ for bicyclists, $67 \%$ for vehicle occupants, $69 \%$ for motorcyclists, and $72 \%$ for pedestrians (28).

Due to the discrepancies between official accident statistics and hospital injury data, the Finnish Consultative Committee on Road Safety has recently taken the responsibility to improve the situation. The aim is to find how the accident statistics by the police and the hospital injury data could be combined.

This study confirms that the official statistics on motorcycle and moped crashes in Finland are insufficient for injury prevention. In order to obtain reliable statistics, compiling accurate data on the crashes and injuries of moped drivers and motorcyclists regularly, in hospital emergency departments, is crucial. It would facilitate an analysis of the trends of these accidents and, more importantly, the use of the data in planning and implementing preventative interventions. The injury data should also include a nationally agreed classification of injury severity. In general, the national traffic safety policy should be based on the actual statistics compiled in hospital emergency departments. According to the recent recommendation of the EU, Finland should report the total number 
of serious traffic injuries (MAIS $\geqslant 3$ ) to the EU for the first time in 2015 (8). Due to this recommendation, severity data will be added as a variable to the accident data compiled by Statistics Finland.

\section{LIMITATIONS}

Our data include only patients who attended hospital emergency departments for treatment and do not, therefore, cover all injured moped drivers and motorcyclists in the region. Drivers who sustained minor injuries could have been treated in local health-care centers. This limitation exists in other studies on this subject, as well (14). Limitations of the present study also include the inability to ascertain the road conditions leading to the accidents, lighting conditions, and the speed of the vehicle at the time of the accident. These factors were not included in the injury database, although they would undoubtedly be important.

Some mopeds may have been tuned up, and their speeds may have exceeded the speed limit of $45 \mathrm{~km} / \mathrm{h}$. However, this is forbidden in Finland, and the Finnish police is very active in controlling the speeds of moped drivers. This possibility could not be checked. This problem has not been mentioned in other studies, either (14-16).

\section{STRENGTHS}

No similar data collection or definition of serious injuries as regards motorcycle and moped crashes has been conducted previously in Finland. The reliability of the primary 2-year injury data, of which the present data are a part, was carefully investigated and found to be good (30). Furthermore, the data of the present study were manually checked and complemented by data on those who were also treated in the central or university hospital of the region in question. The prehospital deaths were checked from Statistics Finland.

\section{CONCLUSION}

According to AIS scores and NISSs, the injury severity was equal for motorcycle and moped crashes. The degree of agreement (overlap) between the hospital dataset and the official statistics was $32 \%$. Thus, the rate of under-reporting was $68 \%$.

\section{DECLARATION OF CONFLICTING INTERESTS}

The authors declare that there is no conflict of interests.

\section{ETHICAL APPROVAL}

Ethical approval was obtained from the Ethics Committees of Kymenlaakso Health Care District and of the Hospital District of Helsinki and Uusimaa.

\section{REFERENCES}

1. Statistics Finland: Road Traffic Accidents 2012, Helsinki 2013 (page 68, Appendix 1), https://www.liikenneturva.fi/sites/ default/files/materiaalit/Tutkittua/Tilastot/tieliikenneonnettomuudet_2012.pdf
2. National Highway Traffic Safety Administration: Traffic Safety Facts: 2007 Data, http://www-nrd.nhtsa.dot.gov/Pubs/ 810990.PDF (2007, accessed October 2010).

3. MonkJP, Buckley R, Dyer D: Motorcycle-related trauma in Alberta: A sad and expensive story. Can J Surg 2009;52:E235-E240.

4. Aare M, von Holst H: Injuries from motorcycle- and moped crashes in Sweden from 1987 to 1999. Inj Contr Saf Promot 2003;10:131-138.

5. Schneiders W, Rollow A, Rammelt S et al: Risk-inducing activities leading to injuries in a child and adolescent population of Germany. J Trauma 2007;62:996-1003.

6. Airaksinen N, Lüthje P, Nurmi-Lüthje I: Cyclist injuries treated in emergency department (ED): Consequences and costs in South-eastern Finland in an area of 100000 inhabitants. Ann Adv Automot Med 2010;54:267-274.

7. Tervo TMT, Neira W, Kivioja A et al: Observational failures/ distraction and disease attack/incapacity as cause(s) of fatal road crashes in Finland. Traffic Inj Prev 2008;9:211-216.

8. Serious Injuries (Vaakku study): Finnish Transport Safety Agency. Research report 10, 2014 (in Finnish, English abstract), http://www.trafi.fi/filebank/a/1416923679/b8f9e9b07b0dc a1231c3958a3c995e52/16298-Trafin_tutkimuksia_10-2014_-Vakavasti_loukkaantuneet.pdf

9. Road Safety: EU reports lowest ever number of road deaths and takes first step towards an injuries strategy, http://ec.europa. eu/commission_2010-2014/kallas/headlines/news/2013/03/ road-safety_en.htm (accessed 18 December 2014).

10. ICD-10: Third edition of the Finnish version of the International Statistical Classification of Diseases and Related Health Problems, 2011, http://www.julkari.fi/bitstream/ handle/10024/80324/15c30d65-2b96-41d7-aca8-1a05aa8a0a19. pdf?sequence $=1$

11. AAAM: The Abbreviated Injury Scale 2005. American Association for Automotive Medicine (AAAM), Des Plaines, IL, 2008.

12. Osler T, Baker SP, Long W: A modification of the injury severity score that both improves accuracy and simplifies scoring. J Trauma 1997;43:922-925.

13. Baker SP, O'Neill B, Haddon W Jr et al: The injury severity score: A method for describing patients with multiple injuries and evaluating emergency care. J Trauma 1974;14:187-196.

14. Barsi T, Faegermann C, Larsen LB: Road traffic accidents with two-wheeled motor vehicle during a five-year period in Odense, Denmark. Traffic Inj Prev 2002;3:283-287.

15. White D, Lang J, Russell G et al: A comparison of injuries to moped/scooter and motorcycle riders in Queensland, Australia. Injury 2013;44:855-862.

16. Leijdesdorff HA, Siegerink B, Frederikus C et al: Injury pattern, injury severity, and mortality in 33,495 hospital-admitted victims of motorized two-wheeled vehicle crashes in The Netherlands. J Trauma 2012;72:1363-1368.

17. Boström L, Wladis A, Nilsson B: Injured moped riders who required admission to hospital in Sweden from 1987 to 1994. Eur J Surg 2002;168:360-365.

18. Wladis A, Boström L, Nilsson B: Injuries in 8927 patients admitted after motorcycle crashes in Sweden 1987-1994 inclusive. Eur J Surg 2002;168:187-192.

19. Wladis A, Boström L, Nilsson B: Injuries and mortality in motorcycle and moped riders in Sweden from $1987-1994$ inclusive. Läkartidningen 2003;100:1238-1241 (in Swedish, English abstract).

20. Kosola S, Salminen P, Laine T: Heading for a fall: Moped and scooter accidents from 2002 to 2007. Scand J Surg 2009;98: $175-179$.

21. Höfling I, Keinänen P, Kröger H: Injuries caused by motorcycle accidents - A 5-year survey of patients treated in Kuopio University Hospital. Finn J Orthop Traumatol 2006;29:243-247, http:/ / www.soy.fi/sot-lehti/3-2006/11.pdf

22. Amin NH, Jakoi A, Katsman A et al: Incidence of orthopaedic surgery intervention in a level I urban trauma center with motorcycle trauma. J Trauma 2011;71:948-951. 
23. Blackman RA, Haworth NL: Comparison of moped, scooter and motorcycle crash risk and crash severity. Accid Anal Prev 2013;57:1-9.

24. Weiss H, Agimi Y, Steiner C: Youth motorcycle-related brain injury by State helmet Law Type: United States, 2005-2007. Pediatrics 2010;126:1149-1155.

25. Mertz KJ, Weiss HB: Changes in motorcycle-related head injury deaths, hospitalization, and hospital charges following repeal of Pennsylvania's mandatory motorcycle helmet law. Am J Public Health 2008;98:1464-1467.

26. Fitzharris M, Dandona R, Kumar GA et al: Crash characteristics and patterns of injury among hospitalized motorised two-wheeled vehicle users in urban India. BMC Public Health 2009;9:11, http:/ / www.biomedcentral.com/1471-2458/9/11

27. Crompton JG, Oyetunji T, Stevens KA et al: Motorcycle helmets save lives, but not limbs: A national trauma data bank analysis of functional outcomes after motorcycle crash. J Surg Res 2010;158:1-5.

28. Cryer PC, Westrup S, Cook AC et al: Investigation of bias after data linkage of hospital admissions data to police road traffic crash reports. Inj Prev 2001;7:234-241.

29. Amoros E, Martin JL, Lafont $S$ et al: Actual incidences of road casualties, and their injury severity, modelled from police and hospital data, France. Eur J Public Health 2008;18:360-365.

30. Lüthje P, Pelkonen J, Nurmi-Lüthje I et al: A community based study of sport and recreation-related injuries treated in Hospital Emergency Department in Finland. Open Sports Med J 2009;3:14-20.

Received: August 31, 2014

Accepted: January 14, 2015 